\title{
The value of coskewness in mutual fund performance evaluation
}

\author{
David Moreno, Rosa Rodríguez*
}

Department of Business Administration, University Carlos III, C/Madrid, 126, Getafe 28903, Spain

\begin{abstract}
A B S T R A C T
Recent asset pricing studies demonstrate the relevance of incorporating coskewness in asset pricing mod els, and illustrate how this component helps to explain the time variation of ex ante market risk premi ums. This paper analyzes the role of coskewness in mutual fund performance evaluation and finds evidence that adding a coskewness factor is economically and statistically significant. It documents that coskewness is sometimes managed and shows persistence of the coskewness policy over time. One of the most striking results is that many negative (positive) alpha funds, measured relative to the CAPM risk adjustments, would be reclassified as positive (negative) alpha funds using a model with coskewness Therefore, performance ranking based on risk adjusted returns without considering coskewness could generate an erroneous classification. Moreover, some fund characteristics, such as turnover ratio or cat egory, are related to the likelihood of managing coskewness.
\end{abstract}

\section{Introduction}

After more than 40 years of research, the problem of how to evaluate active portfolio management remains largely unresolved. Classic performance measures proposed by Treynor (1965), Sharpe (1966), Jensen (1968) were developed assuming a normal distribu tion of returns. During the 1970 s, others realized that these perfor mance measures did not evaluate fund performance accurately because the distribution of fund returns was not Gaussian. Thus, Klemkosky (1973) and Ang and Chua (1979) demonstrated that ignoring the third moment of the return distribution would gener ate a bias in the performance evaluation. This bias could affect investors directly by leading them to create portfolios with a sub optimal asset allocation. ${ }^{1}$

From the asset pricing literature, several authors also point out the convenience of using models with higher moments. Kraus and Litzenberger (1976) document the importance of considering the third moment (skewness) of returns. They develop a model in which investors are compensated for holding systematic risk and coskewness risk, requiring a higher (lower) return whenever the

\footnotetext{
* Corresponding author Tel +34916248641; fax +34916249607

E mail addresses jdmoreno@emp uc3m es (D Moreno), rosa rodriguez@uc3m es (R Rodríguez)

1 Along the same lines, other authors such as Prakash and Bear (1986) or Leland (1999) have developed performance measures incorporating skewness, and Stephens and Proffitt (1991) generalize the performance measure to account for any number of and Proffitt (1991) generalize the performance measure to account for any number of
moments All these results indicate that ignoring higher moments could have a significant impact on the performance rankings of these funds
}

systematic risk is higher (lower) and the coskewness risk is lowe (higher). The negative price of risk in the second component indi cates that investors dislike assets with negative coskewness that requires higher returns. For those unfamiliar with coskewness, an asset with negative coskewness is an asset that, when incorporated into a portfolio, adds negative skewness, increasing the probability of obtaining undesirable extreme values (in the left tail of the distribution).

Given this agreement regarding the importance of higher mo ments from both the mutual fund and asset pricing literatures, re cent studies have started to develop new performance measures. As hedge funds can employ dynamic strategies such as leverage, short selling, and investment in illiquid assets, it seems clear that return distributions will be non normal and that therefore these measures will have a significant effect (see Ranaldo and Favre, 2005; Ding and Shawky, 2007). It is less evident that these mea sures also generate changes in the performance of common mutual funds unable to use those strategies. ${ }^{2}$ Moreno and Rodríguez (2006) have taken the first step of introducing coskewness in mutual fund evaluation for the Spanish case. They find some performance differ ences when these new measures are taken into consideration.

The major contribution of this paper is to provide empirical evi dence about the role of coskewness in evaluating mutual funds. This evidence is not yet addressed in the published literature. It

2 It must be noted that fund managers could use, for example, derivatives (see Koski and Pontiff, 1999; Frino et al , 2009), biasing the distribution of fund returns to the left or right and generating coskewness in the return distribution 
is provided by examining: (a) the changes in the average fund per formance; (b) the variations in the ranking of mutual fund manag ers; (c) the relationships between characteristics such as portfolio turnover, size, category, and coskewness management; and (d) the possibility that some fund managers may profit from the coskew ness spread. Hereafter, "managing coskewness" refers to having a specific policy regarding the assets incorporated into the fund's portfolio to achieve higher or lower portfolio coskewness.

In order to thoroughly study the relevance of including the third co moment of asset returns in performance evaluation, two differ ent multifactor asset pricing models are considered: the CAPM and the Carhart (1997) four factor model. In both models, a coskew ness factor is added and the best adjustment of risk ${ }^{3}$ is sought. The use of a coskewness factor is based on the results from the asset pricing literature, which has demonstrated the convenience of using coskewness models instead of the popular Fama and French (1993) three factor model. Thus, Harvey and Siddique (2000) test the three moment CAPM's implication that a stock with a negative coskewness with the market will earn a higher risk premium. They form a coskewness factor following the methodology that Fama and French use in constructing the SMB and HML factors and find that coskewness is economically significant. Barone Adesi et al. (2004) use a quadratic model and finds that additional variables rep resenting portfolio characteristics (such as those considered in the Fama and French model) have no explanatory power for expected re turns when coskewness is taken into account. Chung et al. (2006) suggest that higher order co moments are important for risk averse investors concerned about extreme outcomes. The authors also find that the risk factors of Fama and French approximate these higher order co moments especially when using low frequencies. Vanden (2006) also points out that SMB and HML measure coskewness risk, but that they are imperfect proxies. More recently, Smith (2007) finds that while the conditional two moment CAPM and the condi tional Fama and French three factor model are rejected, a model that includes coskewness is not rejected by the data. ${ }^{4}$

This paper yields revealing results. First, it finds that the coskewness factor is both economically and statistically signifi cant. Second, the average fund performance will change when coskewness is taken into account; this change is greater when compared with the CAPM alpha (the average alpha for all equity funds is moved to the left side by more than double) than with a Carhart model (the average alpha is modified by approximately $6 \%$ ). Third, in general, these movements in the alpha might affect categories of equity mutual funds in different ways, so that in this sample, the Aggressive Growth funds are made to look better while the rest look worse. Fourth, as those variations in performance will have a different sign depending on the loading on the coskewness factor, a ranking based on risk adjusted returns without consider ing coskewness might result in a misleading classification of the funds. Moreover, one of the most striking results is that many neg ative (positive) alpha funds measured relative to the CAPM risk adjustments would be reclassified as positive (negative) alpha

\footnotetext{
${ }^{3}$ An alternative way to take into account the skewness of the return distribution could be in an equilibrium framework like that of Leland (1999). However, this performance measure would require two assumptions: the rate of return on the market portfolio must be independently and identically distributed and perfect markets must exist. Moreover, many of the econometric problems related to the estimation of the CAPM alpha will also be present in estimating this performance measure, including finding an appropriate proxy for the market portfolio (as mentioned in Leland (1999), footnote 22). In contrast, multifactor pricing models, such as the ones proposed in this paper, are not subject to those problems.

${ }^{4}$ Coskewness is also considered relevant in some other economic areas. For example, Vines et al. (1994) study the importance of coskewness in the pricing of real estate and Christie-David and Chaudhry (2001) examine it in explaining the returngenerating process in futures markets. Bali et al. (2008) investigates the role of conditional skewness in the estimation of conditional VaR. Post et al. (2008) focuses on the 3MCAPM and the economic meaning of the coskewness premium.
}

funds using the CAPM plus coskewness. Fifth, those managers using a specific policy for managing coskewness repeat the same policy over time, thus persistence in coskewness policy appears in the majority of the time periods. Sixth, fund turnover and fund category are related to having a specific policy of managing coskewness.

The remainder of this paper is organized as follows: the follow ing section describes the coskewness measure and the models used to analyze its effect on performance evaluation. Section 3 presents the database of mutual funds and the benchmarks used. Section 4 provides the empirical evidence. Summaries and conclusions are presented in Section 5.

\section{The effect of the coskewness factor on performance evaluation}

\subsection{The coskewness}

Kraus and Litzenberger (1976) extend the CAPM to incorporate the effect of skewness in asset pricing, developing the three mo ment CAPM (3MCAPM). Thus, in equilibrium, the expected returns of a risky asset satisfy:

$R_{i} \quad R_{f}=\lambda_{1} \beta_{i}+\lambda_{2} \gamma_{i}$

where $R_{i}$ is one plus the expected return of the risky asset, $R_{f}$ de notes one plus the return of the risk free asset, $\beta_{i}$ is the systematic risk, and $\gamma_{i}$ indicates the systematic skewness (standardized coskewness) of the asset, a measure of the asset's coskewness risk. ${ }^{5}$ The risk premiums of each risk factor are $\lambda_{1}$ and $\lambda_{2}$. Therefore, inves tors are compensated by the expected excess returns for bearing the relative risks measured by beta and gamma. Given that the investor requires higher returns for securities with higher betas, a positive risk premium, $\lambda_{1}>0$, is expected. However, there would be a nega tive risk premium for assets with positive systematic skewness, $\lambda_{2}<0$.

From an empirical point of view, asset pricing models can be tested through the restrictions that they impose on the coefficients of the return generating process. Thus, the return generating pro cesses consistent with the CAPM and the 3MCAPM are the market model and the quadratic model, respectively. Whereas the market model assumes that the return of a risky asset is linearly related to the return of a stock index representative of the market, the qua dratic model establishes a nonlinear relationship expressed as:

$R_{i, t} \quad f, t=c_{0 i}+c_{1 i}\left[R_{M, t} \quad R_{f, t}\right]+c_{2 i}\left[R_{M, t} \quad \bar{R}_{M, t}\right]^{2}+v_{i t}$.

The estimation of $c_{2 i}$ in the quadratic model (2) gives a coskewness measure. Through the use of a partitioned regression argument (Frisch Waugh Lovell theorem) it is easy to verify that $\mathrm{c}_{2 \mathrm{i}}$ is equal to $E\left(\varepsilon_{i, t+1} \varepsilon_{M, t+1}^{2}\right) / V\left(\varepsilon_{M, t+1}^{2}\right)$, where $\varepsilon_{i, t+1}$ represents the residuals from the regression of the excess return on the contemporaneous market excess return and $\varepsilon_{M, t+1}$ represents the residuals of the excess mar ket return over its mean.

Harvey and Siddique (2000) compute the standardized uncon ditional coskewness as

$S_{i}=\frac{E\left(\varepsilon_{i, t+1} \varepsilon_{M, t+1}^{2}\right)}{\sqrt{E\left(\varepsilon_{i, t+1}^{2}\right) E\left(\varepsilon_{M, t+1}^{2}\right)}}$,

\footnotetext{
${ }^{5}$ According to Kraus and Litzenberger (1976) the expressions are: $\beta_{i}$ $\frac{E\left[\left(R_{i} \bar{R}_{i}\right)\left(R_{M} \bar{R}_{M}\right)\right]}{E\left[\left(R_{M} \bar{R}_{M}\right)^{2}\right]}$ and $\gamma_{i} \frac{E\left[\left(R_{i} \bar{R}_{i}\right)\left(R_{M} \bar{R}_{M}\right)^{2}\right]}{E\left[\left(R_{M} \bar{R}_{M}\right)^{3}\right]}$, where $\gamma_{i}$ is defined as the ratio of the $E\left[\left(R_{M} \bar{R}_{M}\right)^{2}\right]$
coskewness of that asset's return and the market's return to the market's skewness. In the same way that the covariance (the numerator of beta) represents the marginal contribution of an asset to the variance of the market portfolio, the coskewness (the numerator of gamma) represents the asset's marginal contribution to the skewness of the market portfolio.
} 
where $\varepsilon_{M, t+1}$ and $\varepsilon_{i, t+1}$ are defined as above. The information given by the coskewness allows a risk factor to be constructed in the same way that the Fama and French (1993) factors are constructed. This risk factor can be replicated by a portfolio of assets. In order to elab orate on this factor, it is necessary to compute the coskewness mea sure for each asset and then use it to rank the assets. The assets form two portfolios: one contains the $30 \%$ of the assets that have the most negative coskewness $(S$ ) and another contains the 30\% of the assets with the most positive coskewness $\left(S^{+}\right)$. The return spread of the two portfolios $\left(S S^{+}\right)$and the return spread of the portfolio $S$ and the risk free rate $\left(S \quad R_{f}\right)$ are the coskewness risk factors (CSK).

\subsection{The models}

In order to analyze the effect of the coskewness factor on per formance evaluation, the standard CAPM and the Carhart (1997) four factor model are used as base cases. The Carhart (1997) four factor model uses the three factors of Fama and French (1993) plus one that captures the momentum effect. Here, the four factor model (FF4) is used to adjust the performance of the fund for the regularities found in financial returns. Thus, the mod els are

$$
\begin{aligned}
& R_{i, t} \quad R_{f, t}=\alpha_{i}+\beta_{i}^{m}\left[R_{M, t} \quad R_{f, t}\right]+e_{i, t}, \\
& R_{i, t} \quad R_{f, t}=\alpha_{i}+\beta_{i}^{m}\left[R_{M, t} \quad R_{f, t}\right]+\beta_{i}^{\mathrm{smb}} \mathrm{SMB}_{t}+\beta_{i}^{h m l} \mathrm{HML}_{t} \\
& +\beta_{i}^{\mathrm{wml}} \mathrm{WML}_{t}+e_{i, t},
\end{aligned}
$$

where $\left\{R_{M, t} \quad R_{f, t}, \mathrm{SMB}_{t}, \mathrm{HML}_{t}, \mathrm{WML}_{t}\right\}$ represents the market, size, book to market value, and momentum factors.

When a coskewness factor is included,

$$
\begin{aligned}
& R_{i, t} \quad R_{f, t}=\alpha_{i}+\beta_{i}^{m}\left[R_{M, t} \quad R_{f, t}\right]+\beta_{i}^{\mathrm{csk}} \mathrm{CSK}_{t}+e_{i, t}, \\
& R_{i, t} \quad R_{f, t}=\alpha_{i}+\beta_{i}^{m}\left[R_{M, t} \quad R_{f, t}\right]+\beta_{i}^{\mathrm{smb}} \mathrm{SMB}_{t}+\beta_{i}^{\mathrm{hml}} \mathrm{HML}_{t} \\
& +\beta_{i}^{\mathrm{wml}} \mathrm{WML}_{t}+\beta_{i}^{\mathrm{csk}} \mathrm{CSK}_{t}+e_{i, t} .
\end{aligned}
$$

To study the effect of adding this new factor to the traditional Jen sen's alpha, the coskewness risk must be considered in the same way as the systematic market risk. Just as greater returns are re quired for portfolios (and thus managers) with larger systematic risks (betas), in a model that includes coskewness, greater returns are required for portfolios (managers) with larger coskewness risks. To illustrate, evaluate two mutual funds with an annual abnormal return of $3 \%$ as measured by the classic Jensen's alpha,

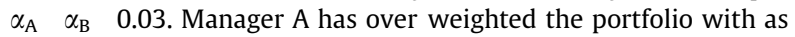
sets that have negative coskewness and has therefore obtained a spread by coskewness, whereas Manager B has not given special consideration to coskewness. According to (6), the loading parame ter that captures the coskewness risk must be positive for Manager A (e.g. $\beta^{\text {CSK }}$ 0.20) and zero for Manager B. Because investors dislike negative coskewness assets that require greater returns, the coskewness factor must have a positive mean (e.g. 0.10), so the final alpha for Manager A will be lower than the alpha for Manager B. Therefore, the abnormal return obtained would be $\begin{array}{llllll}\alpha_{C S K, A} & \alpha_{\mathrm{A}} & \beta_{2}(\mathrm{CSK}) & 0.03 & 0.2(0.10) & 0.01 \text { for Manager } \mathrm{A} \text { and }\end{array}$

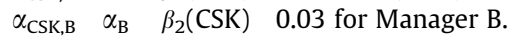

In this example, the manager who tries to profit from the coskewness spread achieves the worse performance. The reason is that alpha is a performance measure that considers risk adjusted returns, so that just as greater returns are required of a manager assuming larger market risk (and therefore a greater $\beta^{\mathrm{m}}$, reducing his Jensen's alpha), greater returns are required of the manager assuming a larger systematic risk of skewness. To complete the argument, it is important to note that Manager A adds negative skewness to the portfolio by incorporating negative coskewness assets, which is an undesirable situation for investors. Thus, a cor rect measure of abnormal returns must penalize this strategy.

\subsection{Conditional performance evaluation}

The models explained above use unconditional expected re turns and are based on the assumption that factor loadings are constant. However, if expected returns and risks vary over time, such an unconditional approach may give biased results. Chen and Knez (1996) and Ferson and Schadt (1996) advocate condi tional performance evaluation (CPE). In their one and multi factor models, factor loadings (betas) are conditioned on public informa tion variables. The resulting conditional Jensen's alphas represent the average difference between the return of a fund and the return of the dynamic strategies based on public information. ${ }^{6}$

Therefore, in this paper, the previous models are analyzed in a conditional and an unconditional framework, given the existing evidence that asset pricing models need to be conditional since ex pected returns vary over time. This analysis contributes to condi tional performance evaluation literature by presenting the differences between conditional and unconditional performance evaluation when coskewness is included.

\section{Data and benchmarks}

\subsection{Fund returns}

The database used in this study consists of monthly returns for 6819 US equity mutual funds between January 1962 and December 2006, obtained from the Center for Research in Security Prices (CRSP). These mutual funds are classified into three categories: Aggressive Growth, Growth Income Funds, and Long Term Growth Funds.

Table 1 provides a complete economic and statistical descrip tion of the database. Presented in rows for each category are the annualized mean return, risk (standard deviation), kurtosis, mini mum and maximum monthly return during the entire sample per iod, and the percentage of funds for which the null hypothesis of normality, using a Jarque Bera test, is rejected. The table also shows the total number of mutual funds in each category in inter vals of 36 84, 84 120, 120 156, 156 288, more than 288, and more than 432 observations.

The figures in Table 1 indicate that the kurtosis is, on average, higher than 3 (a value under the null of a normal distribution) and the null hypothesis of normality is rejected for approximately $48 \%$ of mutual funds (51\% of Aggressive Growth, $53 \%$ of Growth In come Funds, and 44\% of Long Term Growth Funds). According to this result, the use of a performance measure based on normality should be questioned.

\subsection{Benchmark portfolios}

This study uses the CRSP NYSE/AMEX/NASDAQ value weighted index as the market portfolio. The monthly series of SMB, HML, and WML factors obtained from Kenneth French's website ${ }^{7}$ is used to capture the effects of size, book to market value, and momentum. The short term risk free security is the 1 month Treasury bill (from Ibbotson Associates). The predetermined variables used as instru ments in the conditional models are: (1) the lagged level of the

\footnotetext{
${ }^{6}$ Christopherson et al. (1998) propose a refinement of the conditional performance evaluation. Introducing time variation in alpha makes it possible to determine whether managerial performance is indeed constant or varies over time as a function of the conditional information.

${ }^{7}$ http://www.mba.tuck.dartmouth.edu/pages/faculty/ken.french/data library.html
} 
Table 1

Summary statistics of mutual funds: January 1962-March 2006.

\begin{tabular}{|c|c|c|c|c|c|c|c|}
\hline & Mean return & Standard deviation & Kurtosis & Max. losses & Max. returns & Test normality & \\
\hline Aggressive Growth & 11.038 & 21.698 & 4.272 & -18.777 & 17.574 & 51 & \\
\hline Growth/Income & 7.610 & 14.662 & 4.191 & -13.416 & 10.624 & 53 & \\
\hline Long-Term Growth & 7.441 & 17.674 & 4.215 & -15.132 & 13.749 & 44 & \\
\hline \multirow[t]{2}{*}{ All Funds } & 8.595 & 18.206 & 4.272 & -15.854 & 14.192 & 48 & \\
\hline & Number of funds & $36-84$ & $84-120$ & $120-156$ & $156-288$ & $>288$ & $>432$ \\
\hline Aggressive Growth & 2112 & 1054 & 600 & 244 & 169 & 45 & 18 \\
\hline Growth/Income & 1617 & 751 & 426 & 197 & 167 & 76 & 50 \\
\hline Long-Term Growth & 3090 & 1708 & 715 & 366 & 196 & 105 & 61 \\
\hline All Funds & 6819 & 3513 & 1741 & 807 & 532 & 226 & 129 \\
\hline
\end{tabular}

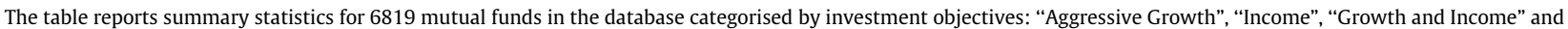

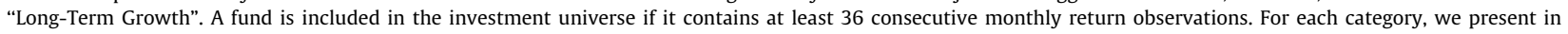

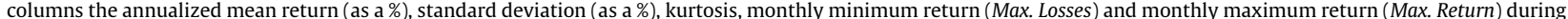

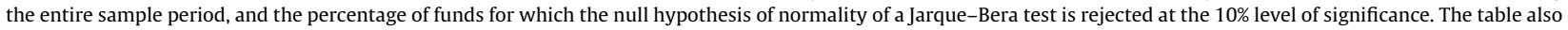
shows the total number of mutual funds in each category in intervals of 36-84, 84-120, 120-156, 156-288 and more than 288 and 432 observations.

one month Treasury bill yields; (2) the lagged dividend yield of the CRSP value weighted NYSE/AMEX/NASDAQ stock index; (3) a lagged measure of the slope of the term structure; and (4) a lagged corpo rate spread on the corporate bond market. The term spread is a con stant maturity 10 year Treasury bond yield minus the 3 month $T$ bill yield. The corporate bond default yield spread is Moody's BAA rated corporate bond yield minus the AAA rated corporate bond yield. These variables have figured most prominently in studies of mutual fund performance (see Ferson and Schadt, 1996; Ferson and Warther, 1996).

Table 2 presents summary statistics on the risk factors. The mean, median, and standard deviation return data are in annual percentages. In addition, the monthly maximum and minimum re turn, and the $p$ value of the Jarque Bera test are shown. The mar ket factor is the excess return on the value weighted index; SMB is the factor mimicking portfolio size; HML is the factor mimicking portfolio book to market value; WML is the factor mimicking port folio 1 month return momentum; and $\left(S \quad S^{+}\right)$and $\left(S \quad R_{f}\right)$ are the coskewness factors.

Monthly US equity returns from CRSP NYSE/AMEX/NASDAQ files from December 1957 to December 2006 are used to compute

Table 2

Summary statistics of risk factors and instruments.

\begin{tabular}{|c|c|c|c|c|c|c|}
\hline & Market & SMB & HML & WML & $S-S^{+}$ & $S-R_{f}$ \\
\hline Mean & 5.453 & 6.118 & 1.973 & 10.184 & 3.190 & 8.755 \\
\hline Median & 9.251 & 6.000 & 1.560 & 10.680 & 2.239 & 8.608 \\
\hline Maximum & 16.049 & 13.630 & 13.420 & 18.400 & 16.384 & 23.005 \\
\hline Minimum & -23.134 & -9.840 & -21.850 & -25.050 & -13.422 & -19.070 \\
\hline Std. dev. & 15.370 & 9.975 & 11.113 & 13.825 & 10.033 & 16.721 \\
\hline Skewness & -0.480 & 0.274 & -0.595 & -0.650 & 0.481 & 0.007 \\
\hline Kurtosis & 4.933 & 5.380 & 8.675 & 8.470 & 6.747 & 4.763 \\
\hline \multirow[t]{3}{*}{ Jarque-Bera } & 0.000 & 0.000 & 0.000 & 0.000 & 0.000 & 0.000 \\
\hline & \multicolumn{2}{|c|}{ Cross correlations } & & & & \\
\hline & Market & SBM & HML & WML & $S-S^{+}$ & $S-R_{f}$ \\
\hline EXRM & 1.000 & & & & & \\
\hline SBM & -0.402 & 1.000 & & & & \\
\hline HML & 0.290 & -0.271 & 1.000 & & & \\
\hline WML & -0.079 & -0.041 & -0.103 & 1.000 & & \\
\hline$S-S^{+}$ & 0.005 & 0.109 & 0.126 & 0.055 & 1.000 & \\
\hline$S-R f^{+}$ & 0.913 & -0.310 & 0.277 & -0.132 & 0.371 & 1.000 \\
\hline
\end{tabular}

This table reports summary statistics on the risk factors. The mean, median and std. dev. are represented in annual percentages. We show the monthly maximum and minimum return, and the $p$-value of the Jarque-Bera test. The Market factor is the excess return on the value-weighted CRSP NYSE/AMEX/Nasdaq portfolio; SMB is the factor mimicking portfolio for size; HML is the factor mimicking portfolio for book-to-market, WML is the factor mimicking portfolio for the 1-month return momentum; $S-S^{+}$and $S-R_{f}$ are the coskewness factors. Table 2 also presents the contemporaneous correlations between the factors included in the models. the coskewness factor, including ordinary common stocks and excluding real estate investment trusts, stocks of companies incor porated outside of the United States, and closed end funds. For robustness, various specifications of the coskewness factor are investigated to ensure that it is not sensitive to its construction methodology. ${ }^{8}$ Thus, there are various cut off definitions (bottom $15 \%$ top $15 \%$ and bottom $20 \%$ top $20 \%$ ) in addition to Harvey and Siddique's (2000) factor (bottom 30\% top 30\%). Moreover, these fac tors are computed by employing the parameter $c_{2}$ from the quadratic model (2) to sort the common stocks instead of using the standard ized unconditional coskewness ( 3 ) proposed by Harvey and Siddique (2000)

The risk premium for all these coskewness factors is positive, becoming higher as the cut off is more extreme. The risk premiums for the $\left(S S^{+}\right)$are $3.44 \%, 3.19 \%$, and $2.33 \%$ annually for the 1515 , 2020 , and 3030 cut offs respectively, and range from $8.9 \%$ to $8.30 \%$ annually in the case of the $\left(S R_{f}\right)$ coskewness factor. Con structing the coskewness factor from the quadratic model, the pre miums for the different cut offs are $3.52 \%, 2.74 \%$, and $2.56 \%$ respectively for the $\left(S S^{+}\right)$, and $9.94 \%, 9.01 \%$, and $8.73 \%$ for the ( $S \quad R_{f}$ ) factor.

In order to analyze the potential impact of the factors when they were added to the models, the correlation coefficient among all of them is computed. The correlation for the same coskewness factor using different cut offs is very high (e.g. for the $\left(\begin{array}{ll}S & \left.S^{+}\right)\end{array}\right.$ 1515 and 2020 the correlation is 0.94 ), allowing the conclusion that the factor is not sensitive to the selection of different cut offs. In addition, the correlation computed using different measures of coskewness is also high, e.g. for the $\left(S S^{+}\right) 3030$ from the Harvey and Siddique measure (2000) and the measure from the quadratic model it is 0.85 . Therefore, the coskewness factor is not sensitive to the different ways of measuring the coskewness.

Table 2 also presents the contemporaneous correlations be tween the factors included in the models. Observe that these cor relations are generally small, ranging from 0.40 to 0.37 . But there is one case in which correlation is not negligible: when the existing correlation between the market factor and the coskewness factor $\left(S \quad R_{f}\right)$ is 0.913 . In order to avoid possible multicollinearity problems, this coskewness factor is orthogonalized with respect to the market factor. The correlation with the market then changes to zero, and the correlation with the other coskewness factor ( $S$ $S^{+}$) changes to 0.90 (whereas before it was only 0.37 ), corroborat ing the robustness of the coskewness factor used here. Conse quently, the rest of the paper shows results only considering the

\footnotetext{
${ }^{8}$ The authors are grateful to an anonymous referee for comments on this section, which have led to substantial improvements in the paper.
} 
Table 3

Skewness and coskewness of mutual funds.

\begin{tabular}{|c|c|c|c|c|}
\hline & All funds & Aggressive Growth & Growth/Income & Long-Term Growth \\
\hline \multicolumn{5}{|c|}{ Panel A: unconditional skewness } \\
\hline Mean & -0.355 & -0.299 & -0.455 & -0.340 \\
\hline Median & -0.399 & -0.327 & -0.470 & -0.391 \\
\hline Positive and Sign. at 5\% & 4.458 & 7.955 & 1.546 & 3.592 \\
\hline Negative and Sign. at 5\% & 49.890 & 42.330 & 61.534 & 48.964 \\
\hline \multicolumn{5}{|c|}{ Panel B: unconditional coskewness } \\
\hline Mean & -0.013 & -0.063 & 0.016 & 0.006 \\
\hline Median & -0.006 & -0.065 & 0.029 & 0.014 \\
\hline Positive and Sign. at $5 \%$ & 7.626 & 4.545 & 8.534 & 9.256 \\
\hline Negative and Sign. at 5\% & 12.011 & 16.241 & 9.895 & 10.227 \\
\hline \multicolumn{5}{|l|}{ Panel C: $C_{2 i}$} \\
\hline Mean & -0.134 & -0.531 & 0.093 & 0.018 \\
\hline Median & -0.018 & -0.543 & 0.127 & 0.083 \\
\hline Positive and Sign. at $5 \%$ & 4.355 & 1.847 & 5.937 & 5.243 \\
\hline Negative and Sign. at 5\% & 5.954 & 8.665 & 5.318 & 4.434 \\
\hline$t$-Statistic & 0.826 & 0.841 & 0.857 & 0.800 \\
\hline
\end{tabular}

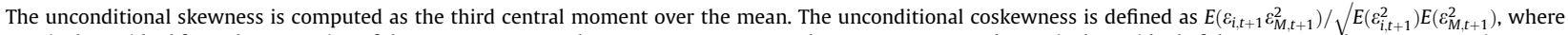

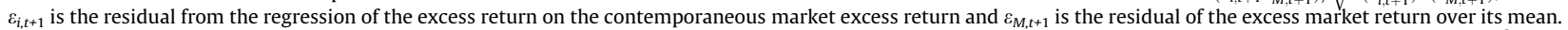

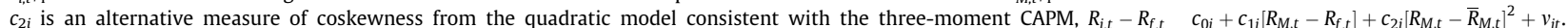

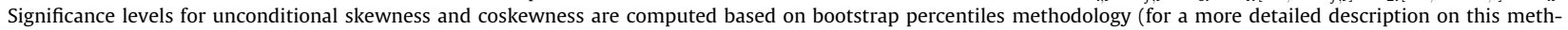

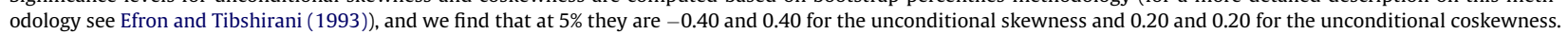

factor $\left(S S^{+}\right)$, where coskewness is computed using (3) and with the intermediate cut off $2020 .^{9}$

\section{Empirical results}

\subsection{The coskewness of mutual funds}

Table 3 reports some summary statistics that compare the coskewness measures across the three categories of funds analyzed in this paper. Panel A shows the unconditional skewness computed as the third central moment over the mean. The results indicate that, considering all funds jointly, half of the funds have a negative skewness, significant at the $5 \%$ level. ${ }^{10}$ For each of the categories, these percentages are $42 \%, 61 \%$, and $49 \%$, respectively. This result shows that the skewness of the funds is significant and that the third moment of the return distribution should not be ignored. Panel B presents the results of measuring the unconditional coskewness of the mutual funds. The mean value for all equity mutual funds is neg ative ( 0.013 ) and the proportion of funds that have a significant coskewness is, on average, $19.63 \%$. Moreover, it can be observed that each category has a different standardized unconditional coskew ness, with the Aggressive Growth being the only one having a nega tive average coskewness ( 0.063 ) and further, having the greatest number of funds with negative unconditional coskewness (16\%). Gi ven that a mutual fund is a portfolio of assets, this finding indicates that approximately $16 \%$ of those mutual funds are investing in assets with negative coskewness and that therefore the required return of these funds according to the 3MCAPM should be higher. When the quadratic model (2) is estimated as an alternative measure of coskewness, the results are similar to those found in Panel B. The mean value estimated for the parameter $c_{2}$, shown in Panel $C$, is neg ative when all categories are considered together and the percentage of funds with a significant parameter is around 10\%. Again, the Aggressive Growth category shows a negative value ( 0.531 ) on

\footnotetext{
${ }^{9}$ The results for the rest of the specifications of the coskewness factor are very similar and are available upon request.

${ }^{10}$ Significance levels for unconditional skewness and coskewness are computed based on bootstrap percentiles methodology (for a more detailed description of this methodology see Efron and Tibshirani, 1993). Here, they are -0.40 and 0.40 for the unconditional skewness and -0.20 and 0.20 for the unconditional coskewness at the $5 \%$ level.
}

average and the Growth Income and Long Term Growth funds pres ent a positive one.

The figures in Table 3 might give the impression that very few funds exhibit significant coskewness and that, as a result, the im pact of coskewness could be marginal. Given that the main goal of the paper is to analyze the importance of coskewness as an addi tional factor in performance evaluation, it is interesting to report the funds' exposure to the coskewness factor rather than just the coskewness measures. The sensitivities to the coskewness factor depend on the factor and the funds. Since, in general, the average betas differ significantly from zero for all categories and factors, using this $\left(S \quad S^{+}\right)$factor, between $58 \%$ and $64 \%$ of the funds are sta tistically significant. ${ }^{11}$

Hence, these results suggest that coskewness could play an important role in explaining the performance evaluation of mutual funds and that disregarding it will create a bias perhaps a signif icant one in assessing performance evaluation. This hypothesis is tested in the following section.

\subsection{Performance evaluation of mutual funds}

The results of the time series estimation for the models are re ported in Table 4 (the first panel reporting all funds jointly and subsequent panels reporting each category of mutual funds). For each panel, Rows 1 and 2 show the unconditional estimation of the CAPM and the CAPM plus the coskewness factor. The Carhart four factor model (1997) and the same model plus the coskewness factor are in Rows 3 and 4. For each model, alpha, beta(s), the ad justed $R^{2}$ of the regressions, and the likelihood ratio test are reported.

An interesting result from Table 4 is that, in general, for all the categories of funds used in this paper and for all models, the aver age coefficient obtained for the CSK factor is statistically different from zero. The values range from 0.09 to 0.10 , depending on the category and the model analyzed. In addition to statistical sig nificance, there is the economic significance. As the coskewness factor is an excess return, an approximate value of the coskewness risk premium can be calculated by multiplying the loadings on the factor by the sample average return of the coskewness portfolio

\footnotetext{
11 These figures are calculated by regressing the excess return of each fund on the returns on the $\left(S-S^{+}\right)$portfolio.
} 
Table 4

Measures of performance using models with and without coskewness.

\begin{tabular}{|c|c|c|c|c|c|c|c|c|}
\hline & Alpha & $R_{\mathrm{m}}$ & SMB & HML & WML & CSK & $R_{\mathrm{ADJ}}^{2}(\%)$ & $\overline{\text { LR-test }}$ \\
\hline \multicolumn{9}{|c|}{ Panel A: All Funds } \\
\hline CAPM & $\begin{array}{r}-0.017 \\
(1.28)\end{array}$ & $\begin{array}{r}0.997 \\
(21.47)\end{array}$ & & & & & 76 & \\
\hline CAPM + CSK & $\begin{array}{r}-0.041 \\
(1.23)\end{array}$ & $\begin{array}{r}1.004 \\
(21.42)\end{array}$ & & & & $\begin{array}{c}0.043 \\
(2.54)\end{array}$ & 78 & 0.023 \\
\hline FF4 & $\begin{array}{c}-0.140 \\
(1.14)\end{array}$ & $\begin{array}{r}1.015 \\
(21.64)\end{array}$ & $\begin{array}{c}0.144 \\
(3.70)\end{array}$ & $\begin{array}{r}0.077 \\
(3.64)\end{array}$ & $\begin{array}{c}0.036 \\
(3.16)\end{array}$ & & 84 & \\
\hline $\mathrm{FF} 4+\mathrm{CSK}$ & $\begin{array}{c}-0.132 \\
(1.15)\end{array}$ & $\begin{array}{r}1.011 \\
(21.90)\end{array}$ & $\begin{array}{c}0.144 \\
(3.64)\end{array}$ & $\begin{array}{r}0.078 \\
(3.28)\end{array}$ & $\begin{array}{r}0.031 \\
(3.05)\end{array}$ & $\begin{array}{c}-0.004 \\
(1.89)\end{array}$ & 85 & 0.104 \\
\hline \multicolumn{9}{|c|}{ Panel B: Aggressive Growth } \\
\hline CAPM & $\begin{array}{r}0.145 \\
(1.20)\end{array}$ & $\begin{array}{r}1.101 \\
(14.54)\end{array}$ & & & & & 66 & \\
\hline CAPM + CSK & $\begin{array}{r}0.133 \\
(1.12)\end{array}$ & $\begin{array}{r}1.096 \\
(14.42)\end{array}$ & & & & $\begin{array}{r}0.033 \\
(2.37)\end{array}$ & 69 & 0.020 \\
\hline FF4 & $\begin{array}{c}-0.174 \\
(1.14)\end{array}$ & $\begin{array}{r}1.118 \\
(16.14)\end{array}$ & $\begin{array}{r}0.406 \\
(5.75)\end{array}$ & $\begin{array}{c}0.134 \\
(4.00)\end{array}$ & $\begin{array}{r}0.131 \\
(3.10)\end{array}$ & & 80 & \\
\hline FF $4+$ CSK & $\begin{array}{c}-0.143 \\
(1.12)\end{array}$ & $\begin{array}{r}1.100 \\
(16.09)\end{array}$ & $\begin{array}{r}0.427 \\
(5.72)\end{array}$ & $\begin{array}{c}0.176 \\
(3.83)\end{array}$ & $\begin{array}{r}0.117 \\
(2.95)\end{array}$ & $\begin{array}{r}-0.090 \\
(1.78)\end{array}$ & 81 & 0.097 \\
\hline \multicolumn{9}{|c|}{ Panel C: Growth Income } \\
\hline CAPM & $\begin{array}{c}-0.071 \\
(1.23)\end{array}$ & $\begin{array}{r}0.855 \\
(28.81)\end{array}$ & & & & & 82 & \\
\hline CAPM + CSK & $\begin{array}{c}-0.132 \\
(1.27)\end{array}$ & $\begin{array}{r}0.884 \\
(29.21)\end{array}$ & & & & $\begin{array}{c}0.099 \\
(2.94)\end{array}$ & 85 & 0.015 \\
\hline FF4 & $\begin{array}{c}-0.102 \\
(1.13)\end{array}$ & $\begin{array}{r}0.891 \\
(29.47)\end{array}$ & $\begin{array}{c}-0.020 \\
(2.85)\end{array}$ & $\begin{array}{c}0.129 \\
(3.54)\end{array}$ & $\begin{array}{c}-0.069 \\
(3.71)\end{array}$ & & 88 & \\
\hline FF4 + CSK & $\begin{array}{r}-0.117 \\
(1.19)\end{array}$ & $\begin{array}{r}0.900 \\
(30.28)\end{array}$ & $\begin{array}{r}-0.038 \\
(2.92)\end{array}$ & $\begin{array}{r}0.093 \\
(3.04)\end{array}$ & $\begin{array}{r}-0.066 \\
(3.64)\end{array}$ & $\begin{array}{r}0.074 \\
(2.34)\end{array}$ & 89 & 0.034 \\
\hline \multicolumn{9}{|c|}{ Panel D: Long-Term Growth } \\
\hline CAPM & $\begin{array}{c}-0.099 \\
(1.36)\end{array}$ & $\begin{array}{r}1.000 \\
(22.36)\end{array}$ & & & & & 79 & \\
\hline CAPM + CSK & $\begin{array}{c}-0.111 \\
(1.29)\end{array}$ & $\begin{array}{r}1.004 \\
(22.12)\end{array}$ & & & & $\begin{array}{r}0.021 \\
(2.44)\end{array}$ & 81 & 0.033 \\
\hline FF4 & $\begin{array}{c}-0.136 \\
(1.14)\end{array}$ & $\begin{array}{r}1.008 \\
(21.29)\end{array}$ & $\begin{array}{r}0.051 \\
(2.73)\end{array}$ & $\begin{array}{r}0.011 \\
(3.45)\end{array}$ & $\begin{array}{r}0.027 \\
(2.92)\end{array}$ & & 86 & \\
\hline $\mathrm{FF} 4+\mathrm{CSK}$ & $\begin{array}{c}-0.132 \\
(1.16)\end{array}$ & $\begin{array}{r}1.007 \\
(21.49)\end{array}$ & $\begin{array}{c}0.046 \\
(2.60)\end{array}$ & $\begin{array}{r}0.002 \\
(3.02)\end{array}$ & $\begin{array}{r}0.023 \\
(2.81)\end{array}$ & $\begin{array}{r}0.014 \\
(1.72)\end{array}$ & 86 & 0.148 \\
\hline
\end{tabular}

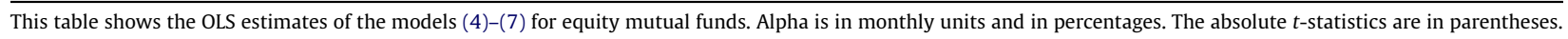

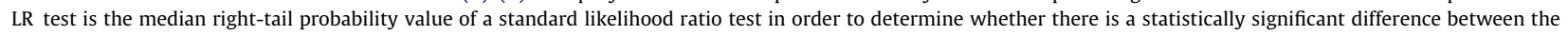
explanatory power of the model with or without the coskewness factor.

(3.19\%). Thus, the average coskewness risk premium ranges from $0.29 \%$ to $0.32 \%$.

In Panel A of Table 4, where all funds are analyzed jointly, there is a slight increase in the $R^{2}$ value when a coskewness factor is used as an additional explanatory variable; this increase being from 0.76 to 0.78 when the coskewness factor is incorporated in the uncon ditional CAPM, and from 0.84 to 0.85 when it is included in the unconditional FF4 model.

The last column in Table 4 reports a standard likelihood ratio (LR) test in order to determine whether there is a statistically sig nificant difference between the explanatory power of the new model with coskewness and the previous model. The introduction of this extra factor leads to an increase in log likelihood, indicating the relevance of the coskewness. The explanatory power of the coskewness model increases significantly over each corresponding model without this new factor, especially relevant in the case of the Aggressive Growth and Growth Income funds for every model, and in the Long Term Growth category only for the CAPM. There fore, not incorporating the effect of the systematic skewness may create a potential problem of specification that biases the risk ad justed return obtained by mutual funds.

Table 4 also reports the average alphas and their $t$ statistic. In general they are close to zero and negative except for the estima tion of the CAPM for the Aggressive Growth category where the al phas are positive. Although the average alphas are not statistically significant in any case, the economic significance of the effect of coskewness on the performance of a fund is not negligible. For example, from Table 4, when comparing the mean alpha from the CAPM and that from the CAPM + CSK, alpha decreases by 0.024 percent per month, from 0.017 to 0.041 , after coskew ness is controlled. Thus, the net effect of coskewness on alpha is approximately $0.28 \%(0.024 \times 12)$ annually.

However, it must be noted that the average change in perfor mance, measured by alpha, is not uniform across categories and models. First, when coskewness is included in the CAPM, the change in alpha is always greater than when it is included in the FF4 model. Second, when comparing performance among different categories, accounting for the coskewness generally makes the funds belonging to the Growth Income and Long Term Growth cat egories look worse, but the funds in the Aggressive Growth cate gory look better. Furthermore, it is important to note that looking only at average alphas may erroneously lead to the conclu sion that the economic impact of coskewness on performance is negligible. This is because within a fund sample, there may be managers with a positive beta for the coskewness factor (which would imply a decrease in alpha, as these funds have greater expo sure to assets with negative coskewness which is undesirable for the investor) and managers with a negative beta for the coskew ness factor (which would imply an increase in alpha). Therefore, coskewness may have a negligible impact on the average alpha, even if its effect on individual alphas is significant. This argument suggests that a more detailed analysis is needed to assess the im 
Table 5

Measures of performance using conditional models with and without coskewness.

\begin{tabular}{|c|c|c|c|c|c|c|c|c|c|c|}
\hline & Alpha & CSK & $R_{\mathrm{ADJ}}^{2}(\%)$ & LR-test & Pval $F$ & Alpha & CSK & $R_{\mathrm{ADJ}}^{2}(\%)$ & LR-test & Pval $F$ \\
\hline & \multicolumn{5}{|c|}{ Panel A: All Funds } & \multicolumn{5}{|c|}{ Panel B: Aggressive Growth } \\
\hline CAPM & $\begin{array}{r}-0.012 \\
(1.21)\end{array}$ & & 78 & & 0.10 & $\begin{array}{r}0.178 \\
(1.06)\end{array}$ & & 68 & & 0.18 \\
\hline CAPM + CSK & $\begin{array}{c}-0.034 \\
(1.20)\end{array}$ & $\begin{array}{c}0.040 \\
(2.24)\end{array}$ & 80 & 0.04 & 0.16 & $\begin{array}{c}0.149 \\
(1.01)\end{array}$ & $\begin{array}{c}0.042 \\
(2.10)\end{array}$ & 70 & 0.040 & 0.26 \\
\hline FF4 & $\begin{array}{r}-0.117 \\
(1.10)\end{array}$ & & 85 & & 0.17 & $\begin{array}{c}-0.114 \\
(1.03)\end{array}$ & & 81 & & 0.22 \\
\hline $\mathrm{FF} 4+\mathrm{CSK}$ & $\begin{array}{l}-0.113 \\
(1.14)\end{array}$ & $\begin{array}{l}-0.009 \\
(1.81)\end{array}$ & 86 & 0.103 & 0.18 & $\begin{array}{l}-0.093 \\
(1.05)\end{array}$ & $\begin{array}{l}-0.094 \\
(1.69)\end{array}$ & 82 & 0.104 & 0.24 \\
\hline CAPM & $\begin{array}{r}\text { Panel C } \\
-0.122 \\
(1.26)\end{array}$ & Income & 84 & & 0.05 & $\begin{array}{c}\text { Panel D: } \\
-0.084 \\
(1.28)\end{array}$ & erm Grow & 81 & & 0.10 \\
\hline CAPM + CSK & $\begin{array}{r}-0.157 \\
(1.33)\end{array}$ & $\begin{array}{r}0.081 \\
(2.57)\end{array}$ & 86 & 0.026 & $\begin{array}{l}0.08 \\
0.10\end{array}$ & $\begin{array}{c}-0.095 \\
(1.25)\end{array}$ & $\begin{array}{c}0.017 \\
(2.16)\end{array}$ & 83 & 0.049 & 0.14 \\
\hline FF4 & $\begin{array}{c}-0.128 \\
(1.19)\end{array}$ & & 89 & & 0.09 & $\begin{array}{c}-0.114 \\
(1.10)\end{array}$ & & 87 & & 0.16 \\
\hline $\mathrm{FF} 4+\mathrm{CSK}$ & $\begin{array}{r}-0.138 \\
(1.27)\end{array}$ & $\begin{array}{c}0.069 \\
(2.25)\end{array}$ & 90 & 0.034 & 0.09 & $\begin{array}{r}-0.113 \\
(1.13)\end{array}$ & $\begin{array}{r}0.007 \\
(1.66)\end{array}$ & 87 & 0.143 & 0.17 \\
\hline
\end{tabular}

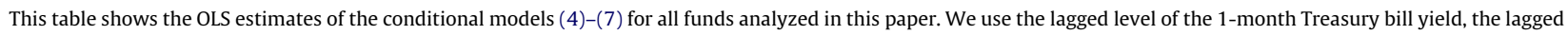

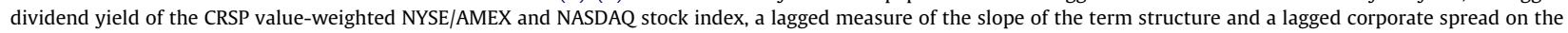

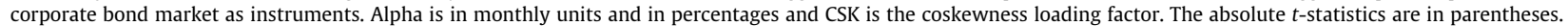

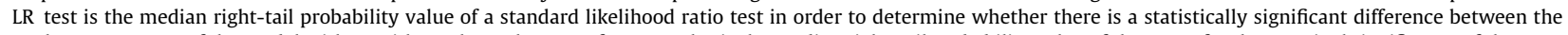

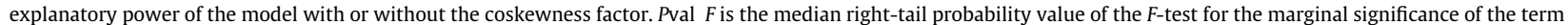
including the instruments.

pact of coskewness on performance. In particular, the analysis should pay special attention to the coskewness management strat egy implemented by fund managers. In the following subsection, the funds will be grouped according to their sensitivity to the coskewness factor.

The estimation of the conditional models presented in Table 5 shows that the signs for the loadings on the coskewness factor are the same as in the unconditional estimations, and also that they are statistically significant. According to the LR test, in general there is a statistically significant increment in the explanatory power of the model with coskewness, clearer in the CAPM models than in the FF4 models, and clearer for the Growth Income cate gory. An $\mathrm{F}$ test is performed for the marginal explanatory power of conditioning information in the models. In this sample, the $F$ test shows that, considered together, the instruments are not sig nificant at the $5 \%$ level. ${ }^{12}$ Therefore, given that the conditional mod els seem not to contribute significantly, the rest of the paper focuses on the unconditional models.

Table 6 displays the distribution of the $t$ statistics for alpha coefficients to analyze whether the coskewness factor significantly changes the distribution of alphas. The figures in each column of the body of the table are the percentages of mutual funds in which the $t$ statistics for the alphas fall within the range of values indi cated in the far left hand column. Panel A of Table 6 reports the unconditional models using the CAPM as a base case and Panel B the unconditional FF4 model. In general, when systematic skew ness is considered, the distribution of the alphas moves slightly to the left, indicating that the coskewness factor makes the average performance of fund managers look worse.

If the coskewness factor is added to the unconditional CAPM, the percentage of negative and significant alphas increases by be tween $1 \%$ and $6 \%$, depending on the category of funds. The larger increases from $21 \%$ to $27 \%$ are obtained in the Growth Income funds. In the case of adding the coskewness factor to the FF4 model the results depend a lot on the category. While in Growth Income

\footnotetext{
12 Ferson and Schadt (1996) find $p$-values of 0.06 for this test in a different sample, from 1968 to 1990 .
}

Table 6

Distribution of $t$-statistics for the alpha coefficients.

\begin{tabular}{|c|c|c|c|c|c|c|c|c|}
\hline & \multicolumn{4}{|c|}{ CAPM } & \multicolumn{4}{|c|}{ CAPM + CSK } \\
\hline & ALL & AG & GI & LTG & ALL & AG & GI & LTG \\
\hline \multicolumn{9}{|l|}{ Panel A } \\
\hline Bonferroni $p$-value & 0 & 0 & 0 & 0 & 0 & 0 & 0 & 0 \\
\hline$t<-2.291$ & 10 & 3 & 12 & 15 & 10 & 3 & 13 & 14 \\
\hline$-2.291<t<-1.995$ & 4 & 1 & 4 & 5 & 5 & 2 & 6 & 5 \\
\hline$-1.995<t<-1.666$ & 5 & 2 & 5 & 6 & 5 & 2 & 8 & 6 \\
\hline$-1.666<\mathrm{t}<0$ & 37 & 32 & 43 & 38 & 40 & 31 & 49 & 42 \\
\hline $0<t<1.666$ & 33 & 40 & 30 & 28 & 32 & 46 & 21 & 27 \\
\hline $1.666<t<1.995$ & 3 & 6 & 2 & 2 & 3 & 6 & 1 & 2 \\
\hline $1.995<t<2.291$ & 3 & 5 & 2 & 2 & 2 & 5 & 1 & 1 \\
\hline$t>2.291$ & 6 & 11 & 2 & 4 & 3 & 6 & 1 & 3 \\
\hline \multirow[t]{3}{*}{ Bonferroni $p$-value } & 0 & 0 & 0.01 & 0.02 & 0 & 0 & 0 & 0.19 \\
\hline & \multicolumn{4}{|l|}{ FF4 } & \multicolumn{4}{|c|}{$\mathrm{FF} 4+\mathrm{CSK}$} \\
\hline & ALL & AG & GI & LTG & ALL & AG & GI & LTG \\
\hline \multicolumn{9}{|l|}{ Panel B } \\
\hline Bonferroni $p$-value & 0 & 0 & 0 & 0 & 0 & 0 & 0 & 0 \\
\hline$t<-2.291$ & 10 & 9 & 10 & 11 & 10 & 8 & 11 & 10 \\
\hline$-2.291<t<-1.995$ & 4 & 4 & 5 & 5 & 5 & 4 & 5 & 6 \\
\hline$-1.995<t<-1.666$ & 7 & 7 & 6 & 7 & 6 & 5 & 7 & 7 \\
\hline$-1.666<t<0$ & 50 & 50 & 52 & 49 & 49 & 49 & 52 & 49 \\
\hline $0<t<1.666$ & 26 & 27 & 26 & 25 & 25 & 29 & 22 & 24 \\
\hline $1.666<t<1.995$ & 1 & 2 & 1 & 1 & 2 & 2 & 1 & 2 \\
\hline $1.995<t<2.291$ & 1 & 1 & 0 & 1 & 1 & 1 & 0 & 1 \\
\hline$t>2.291$ & 1 & 1 & 1 & 1 & 1 & 2 & 1 & 1 \\
\hline Bonferroni $p$-value & 0 & 0 & 1 & 1 & 0 & 0 & 0.51 & 1 \\
\hline
\end{tabular}

The numbers in each column of the table are the percentages of mutual funds for which the $t$-statistics for the alphas fell within the range of values indicated in the far-left-hand column. In Panel A we show the models using the CAPM as a base case. In Panel B the base case is the FF4 model. Inside each type of model, in columns, we present each of the categories of funds: ALL (All Funds), AG (Aggressive Growth Funds), GI (Growth Income Funds) and LTG (Long-Term Growth Funds). The Bonferroni $p$-value indicates the $p$-values based on the Bonferroni inequality. This is computed as the $p$-value (one-tailed) associated with the maximum or minimum $t$ statistic, multiplied by the number of funds. It tests the hypothesis that all the alphas are zero against the alternative that at least one is positive (maximum value) or negative (minimum value).

the negative and significant alphas increase from $21 \%$ to $23 \%$, in the Aggressive Growth category they decrease from $20 \%$ to $17 \%$. 
Table 7

The significance of coskewness in performance.

\begin{tabular}{|c|c|c|c|c|c|c|}
\hline & $\beta^{\mathrm{CSK}}$ & CAPM $(\alpha \%)$ & CAMP + CSK $(\alpha \%)$ & $\beta^{\mathrm{CSK})}$ & FF4 $(\alpha \%)$ & $\mathrm{FF} 4+\operatorname{CSK}(\alpha \%)$ \\
\hline \multicolumn{7}{|c|}{ All Funds } \\
\hline Q1 & -0.30 & -0.14 & $0.04^{* * *}$ & -0.27 & -0.15 & $-0.08^{* * *}$ \\
\hline Q2 & -0.09 & -0.14 & $-0.09^{* * *}$ & -0.09 & -0.16 & -0.14 \\
\hline Q3 & 0.07 & -0.08 & $-0.12^{* * *}$ & 0.02 & -0.13 & -0.13 \\
\hline Q4 & 0.19 & 0.07 & $-0.04^{* * *}$ & 0.12 & -0.16 & -0.16 \\
\hline Q5 & 0.35 & 0.21 & $0.00^{* *}$ & 0.20 & -0.11 & $-0.14^{* *}$ \\
\hline \multicolumn{7}{|c|}{ Aggressive Growth } \\
\hline Q1 & -0.44 & -0.04 & $0.22^{* * *}$ & -0.37 & -0.14 & $-0.06^{* * *}$ \\
\hline Q2 & -0.17 & 0.04 & $0.14^{* * *}$ & -0.23 & -0.16 & $-0.11^{*}$ \\
\hline Q3 & 0.06 & 0.06 & 0.03 & -0.10 & -0.16 & -0.15 \\
\hline Q4 & 0.27 & 0.17 & $0.05^{* * *}$ & 0.04 & -0.16 & -0.16 \\
\hline Q5 & 0.44 & 0.50 & $0.23^{* * *}$ & 0.21 & -0.24 & -0.24 \\
\hline \multicolumn{7}{|c|}{ Growth Income } \\
\hline Q1 & -0.13 & -0.19 & $-0.13^{* * *}$ & -0.08 & -0.15 & -0.14 \\
\hline Q2 & 0.02 & -0.17 & -0.18 & 0.02 & -0.13 & -0.13 \\
\hline Q3 & 0.09 & -0.11 & $-0.16^{* * *}$ & 0.09 & -0.09 & -0.11 \\
\hline Q4 & 0.20 & 0.04 & $-0.08^{* * *}$ & 0.13 & -0.06 & $-0.09^{*}$ \\
\hline Q5 & 0.32 & 0.07 & $-0.12^{* * *}$ & 0.22 & -0.07 & $-0.12^{* * *}$ \\
\hline \multicolumn{7}{|c|}{ Long-Term Growth } \\
\hline Q1 & -0.27 & -0.22 & $-0.07^{* *}$ & -0.20 & -0.14 & $-0.09^{* * *}$ \\
\hline Q2 & -0.11 & -0.21 & $-0.14^{* * *}$ & -0.07 & -0.15 & -0.14 \\
\hline Q3 & 0.03 & -0.18 & -0.20 & 0.02 & -0.12 & -0.12 \\
\hline Q4 & 0.14 & -0.04 & $-0.12^{* * *}$ & 0.11 & -0.15 & -0.16 \\
\hline Q5 & 0.31 & 0.15 & $-0.03^{* * *}$ & 0.21 & -0.12 & $-0.15^{* * *}$ \\
\hline
\end{tabular}

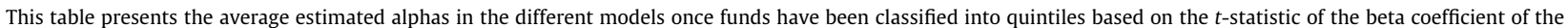

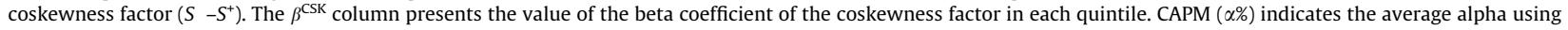

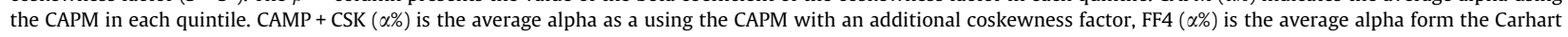
model, and FF4 + CSK $(\alpha \%)$ is the average alpha form a Carhart model including the coskewness factor.

" Means significance at the $10 \%$ level for the Wilcoxon test of differences in alpha distribution between the model with and without coskewness.

Means significance at the $5 \%$ level for the Wilcoxon test of differences in alpha distribution between the model with and without coskewness.

\subsection{The effect of coskewness and the coskewness policy}

As stated in the previous section, the net effect of considering coskewness and mutual fund performance cannot be analyzed only by the changes in the average alpha, given that different mutual funds have different exposure to the coskewness factor. Funds with negative sensitivity to the coskewness factor add assets with posi tive coskewness to their portfolios and therefore investors will de mand lower returns for these funds. The average alpha (adjusted by the risk of coskewness) should then be higher. However, those funds that incorporate negative coskewness assets must present a positive beta of coskewness and investors will demand higher re turns due to the higher risk of coskewness; in that case, the ad justed alpha should be lower. Given this, the net effect over the average alpha may seem small because the effects of both types of funds are mutually balanced. It could be erroneously concluded that coskewness has a negligible effect on mutual fund perfor mance when in fact, as Table 6 shows, this is not the case.

Table 7 shows the average estimated alpha in the different models once the funds have been classified into quintiles according to the significance of the beta to the coskewness factor. This table shows that there are clearly opposite effects on a mutual fund's al pha depending on the sign of the loading factor of coskewness. For example, considering all funds jointly in the first quintile (that is, the $20 \%$ of the funds with the lowest exposure to the CSK factor), the alpha changes from a negative value of 0.14 to a positive va lue of 0.04 ; this variation in means is statistically significant at the $5 \%$ level. For the FF4 model the change in alpha is also significant using all the funds jointly. Similarly, for the $20 \%$ of funds with the greatest sensitivity to the CSK factor (Q5), the effect on alpha is the opposite, moving from a positive value of 0.21 to a value of 0.00 , and the variation in means is also statistically significant. Logically, these changes are not statistically significant for the cen tral quintiles formed by funds that do not manage coskewness. Therefore, using the coskewness factor allows correcting for the performance of funds managing coskewness while not affecting those not managing coskewness.

A second outcome observed in Table 7 is that a ranking based on risk adjusted returns without considering coskewness might result in a contrary classification for the funds in the extreme quintiles, where losers would be considered winners and vice versa. For example, in the CAPM the mean alphas for quintiles 1 and 5 are

$0.14 \%$ and $0.21 \%$ respectively, but when the coskewness factor is considered the mean alphas change to $0.04 \%$ and $0.00 \%$, respec tively. Moreover, the Wilcoxon test shows how the average alphas are significantly different in these extreme quintiles.

Analyzing categories, the conclusions are identical. However, the different effect obtained in the Aggressive Growth and Growth Income funds must be emphasized. Taking into account the coskewness for the former in a FF4 model, the change in alphas is only statistically significant in the first and second quintiles, indicating a better performance for this category of funds. How ever, in the case of the Growth Income category, the change in mean alphas is only statistically significant in the last two quintiles (Q4 and Q5), generating a worse performance for this category. It must be noted that this result is in accordance with the movement in alphas observed for the FF4 model in Table 6.

In conclusion, there is evidence of significant changes in mutual fund performance when the systematic skewness is considered; it is a different sign depending on the fund's exposure to the coskew ness factor. Moreover, these changes in performance are statisti cally significant in $80 \%$ of the mutual funds sampled (Q1, Q2, Q4, and Q5) when the coskewness is introduced in the CAPM, and are statistically significant for between $20 \%$ and $40 \%$ in the FF 4 model. ${ }^{13}$ Once more, these conclusions are consistent independent of the coskewness factor employed here. Consequently, these results

\footnotetext{
13 The lower impact of coskewness in the FF4 model indicates that, as Chung et al. (2006) and Vanden (2006) pointed out, Fama and French risk factors may be proxying higher order co-moments.
} 
might have serious effects on other mutual fund research where per formance ranking is required, such as persistence studies or studies of investors' selection ability and flows of mutual funds.

\subsection{Persistence managing coskewness}

Thus far, the analysis of coskewness has used a 44 year sample. In such a long period, it is quite likely that the coskewness of the funds has varied over time. ${ }^{14}$ Instead of assuming that the coskew ness betas have remained constant over the whole period, it would be interesting to estimate them over shorter periods to appreciate, by categories, whether the coskewness beta changes in magnitude and sign between periods. In this section, the models presented in Table 4 are estimated again, splitting the sample into three subsam ples: 1962 1976, 1977 1991, and 1992 2006. Table 8 reports these estimations. The alpha with and without coskewness and the beta of the CSK factor are presented for each model to analyze the sign and significance of this parameter in each subsample.

The results show that the coskewness policy does not seem con stant, given that the beta for the CSK factor has varied over time. Thus, for example, from subperiod 1 to 2, every category changes from a negative and significant beta to a positive one (e.g. Aggres sive Growth goes from 0.182 to 0.175 ) when the CAPM is consid ered. When the FF4 model is considered, there is also a change in sign from subperiod 1 to 2 for the majority of categories. From sub period 2 to 3, there is only a change in sign of the coskewness beta for the Aggressive Growth and Growth Income categories when the FF4 model is used.

Hence, these results highlight the need to consider coskewness when evaluating the performance of mutual funds because, depending on the time period, coskewness affects them in different ways. ${ }^{15}$ In addition, Table 8 shows that the coskewness factor is especially significant in the third time period for all models and categories. $^{16}$

On the other hand, after the previous analysis, it is unknown if the coskewness policy of a particular manager remains constant over time, because the funds have been aggregated in categories. However, Table 7 shows that within the same category there are funds with positive sensitivity and funds with negative sensitivity to the coskewness factor. Therefore, from an economic point of view it would be interesting to find out if certain managers might be keeping a constant coskewness policy over time and whether they may be profiting from the spread of coskewness.

A non parametric methodology based upon contingency tables is used to study this question: a contingency table of funds called "positives" and "negatives," where a fund is termed positive if its sensitivity to the coskewness factor is positive, and negative if it is not. The analysis is similar to persistence performance studies. However, in this context, persistence indicates those funds that are positive in two consecutive periods, denoted by PP, or negative in two consecutive periods, denoted by NN. Similarly, positive (negative) in the first period and negative (positive) in the second period, denoted by PN (NP), indicates a reversal behavior. This con tingency analysis requires division of the sample into subperiods, as well as funds that exist in two consecutive periods. Here, there are subperiods of 3 years, although in a context of two periods. Thus, period 62/64 65/67 indicates that the beta of the factor

\footnotetext{
${ }^{14}$ Smith (2007) finds evidence that coskewness is time-varying and rejects the null hypothesis of constant coskewness.

${ }^{15}$ The analysis has also been repeated for only two subsamples (1962-1980 and 1981-2006) and the results are very similar; they are available upon request.

${ }^{16}$ In the second subsample (January 1977-December 1991) the absolute $t$-statistics for the coskewness beta are not statistically significant on average, but this is because of the extreme return on the crack of October 1987. If the models are estimated without this date, then all the $t$-statistics for beta coskewness are statistically significant, as in the third subsample.
}

coskewness is considered for period 62/64 and is compared with that obtained in the $65 / 67$ period. ${ }^{17}$

A Cross Product Ratio (CPR) is used to detect persistence in managing coskewness. ${ }^{18}$ The CPR reports the odds ratio of the num ber of managers that repeat to the number of those that do not re peat, that is, $(\mathrm{PP} * \mathrm{NN} / \mathrm{PN} * \mathrm{NP})$. The null hypothesis that the coskewness policy in the first period is unrelated to the coskewness policy in the second corresponds to an odds ratio of one. Table 9 re ports the test statistic for the odds ratio test. ${ }^{19}$ In Panel A the analysis is carried out using all mutual funds in the database, and in Panel B only those funds that really manage the coskewness are considered (funds with a statistically significant beta of coskewness).

Independent of the coskewness factor used in Panel A, in gen eral there are some cases in which there is a persistence in manag ing coskewness (this number is higher when the CAPM is used) but also a similar number of cases for reversals (e.g. using the CAPM, the proportion of cases of persistence against reversals is $14 / 1$, and using the FF4 model, it decreases to 7/7). Thus, it could be erro neously concluded that there is not a persistence behavior from mutual fund managers in managing coskewness. As mentioned above, reversals appear when managers change their coskewness policy. However, these reversals could also be generated uninten tionally, that is, when non significant betas are changing from po sitive to negative or vice versa, but are not statistically significant. This would be the case of fund managers who have no specific coskewness policy. In order to verify this issue, those funds with a significant beta of coskewness are analyzed exclusively.

Panel B presents the results for those mutual funds with a coskewness beta statistically significant at $5 \%$. Once the funds that truly take a policy of coskewness are studied separately, in practi cally all cases independence is rejected and the reversal pattern disappears. Therefore, the results indicate that fund managers with a certain policy of managing coskewness tend to maintain it over time and that this persistence seems to be more relevant in the la ter time periods (it could also be due to the very low number of funds at the beginning of the sample). Moreover, that persistence behavior is sensitive to the model used, being clearer when intro ducing the coskewness factor in a CAPM.

\subsection{Mutual fund characteristics and coskewness}

These results suggest that some fund managers are managing the coskewness of their portfolios. The next logical objective would be to investigate the characteristics of those funds. Are they the largest or the smallest funds? Do they have a higher or lower ex pense ratio? Do they have a higher or lower turnover ratio? To shed some light on these questions, two different analyses are per formed: a univariate analysis of the mean of some characteristics after separating the funds into three different groups according to their coskewness, and then a multinominal logit model to esti mate the probability of a fund having a significant coskewness con ditional on the explanatory variables.

Now, group $(S)$ includes the $15 \%$ of funds with the most nega tive unconditional coskewness, $\left(S^{+}\right)$the $15 \%$ with the most positive coskewness, and $\left(S^{0}\right)$ the rest of the funds. Given the results of Ta ble 3 , this result is similar to separating the funds with significant coskewness (especially negative coskewness) from the funds with out significant coskewness. The characteristics considered are To

\footnotetext{
17 In addition to subperiods of 3 years, the analysis has also been repeated with subperiods of 5 years and the results and conclusions are identical.

18 There is also a $\chi^{2}$ test comparing the observed frequency distribution of PP, PN, $\mathrm{NP}$, and NN for each fund with the expected frequency distribution. Given that the conclusions are identical, they not shown to save space, but are available upon request.

${ }^{19}$ The statistical significance of the CPR is determined by using the standard error of the natural logarithm of the CPR (see Christensen (1990) for more details).
} 
Table 8

The coskewness beta by subperiods.

\begin{tabular}{|c|c|c|c|c|c|c|}
\hline & \multicolumn{2}{|c|}{ Panel A: 1962-1976 } & \multicolumn{2}{|c|}{ Panel B: 1977-1991 } & \multicolumn{2}{|c|}{ Panel C: 1992-2006 } \\
\hline & $(\alpha \%)$ & $\beta^{\mathrm{CSK}}$ & $(\alpha \%)$ & $\beta^{\mathrm{CSK}}$ & $(\alpha \%)$ & $\beta^{\mathrm{CSK}}$ \\
\hline \multicolumn{7}{|l|}{ All Funds } \\
\hline CAPM & 0.063 & & 0.013 & & -0.022 & \\
\hline CAPM + CSK & 0.074 & $-0.089^{* *}$ & 0.009 & 0.079 & -0.046 & $0.043^{* * *}$ \\
\hline FF4 & 0.067 & & 0.056 & & -0.152 & \\
\hline $\mathrm{FF} 4+\mathrm{CSK}$ & 0.081 & $-0.085^{* *}$ & 0.054 & 0.011 & -0.144 & $-0.005^{* *}$ \\
\hline \multicolumn{7}{|c|}{ Aggressive Growth } \\
\hline CAPM & -0.070 & & 0.016 & & 0.146 & \\
\hline CAPM + CSK & -0.048 & $-0.182^{* *}$ & 0.007 & $0.175^{*}$ & 0.136 & $0.030^{* *}$ \\
\hline FF4 & -0.007 & & 0.129 & & -0.192 & \\
\hline $\mathrm{FF} 4+\mathrm{CSK}$ & 0.020 & $-0.159^{* *}$ & 0.125 & 0.017 & -0.159 & $-0.097^{* *}$ \\
\hline \multicolumn{7}{|l|}{ Growth Income } \\
\hline CAPM & 0.046 & & -0.028 & & -0.073 & \\
\hline CAPM + CSK & 0.052 & $-0.072^{* * *}$ & -0.022 & 0.007 & -0.140 & $0.106^{* *}$ \\
\hline FF4 & -0.007 & & -0.021 & & -0.108 & \\
\hline $\mathrm{FF} 4+\mathrm{CSK}$ & 0.005 & $-0.067^{* * *}$ & -0.019 & -0.003 & -0.124 & $0.079^{* * *}$ \\
\hline \multicolumn{7}{|c|}{ Long-Term Growth } \\
\hline CAPM & 0.129 & & 0.044 & & -0.108 & \\
\hline CAPM + CSK & 0.139 & $-0.062^{*}$ & 0.035 & 0.067 & -0.121 & $0.020^{* *}$ \\
\hline FF4 & 0.148 & & 0.064 & & -0.149 & \\
\hline $\mathrm{FF} 4+\mathrm{CSK}$ & 0.158 & $-0.068^{* *}$ & 0.060 & 0.018 & -0.144 & $0.013^{*}$ \\
\hline
\end{tabular}

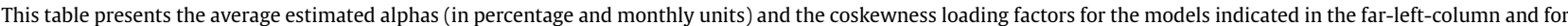
three subsamples (Panel A: 1962-1976; Panel B: 1977-1991; and Panel C: 1992-2006).

"Means significance at the $10 \%$ level.

*** Means significance at the $5 \%$ level.

Table 9

Non-parametric tests of persistence in coskewness policy.

\begin{tabular}{|c|c|c|c|c|c|c|}
\hline & \multicolumn{3}{|l|}{ CAPM } & \multicolumn{3}{|l|}{ FF4 } \\
\hline & Aggressive Growth & Growth Income & Long-Term Growth & Aggressive Growth & Growth Income & Long-Term Growth \\
\hline \multicolumn{7}{|c|}{ Panel A: analysis with all mutual funds in the database } \\
\hline $62 / 64-65 / 67$ & -0.23 & 1.05 & 0.81 & 0.49 & -0.70 & 0.35 \\
\hline $65 / 67-68 / 70$ & -0.41 & 1.18 & 0.00 & $1.65^{*}$ & 0.92 & $2.16 *$ \\
\hline $68 / 70-71 / 73$ & 0.36 & 0.31 & 0.22 & -0.92 & -0.24 & -0.54 \\
\hline $71 / 73-74 / 76$ & 0.15 & 0.62 & 0.51 & 0.93 & 0.05 & 0.46 \\
\hline $74 / 76-77 / 79$ & -0.12 & $1.67^{*}$ & -0.82 & 1.24 & -0.91 & 0.23 \\
\hline $77 / 79-80 / 82$ & 0.60 & 1.10 & 0.37 & -0.52 & $1.46^{*}$ & 1.15 \\
\hline $80 / 82-83 / 85$ & 0.47 & $2.17^{* *}$ & $3.62^{* *}$ & 0.65 & $2.42^{* * *}$ & $1.35^{*}$ \\
\hline $83 / 85-86 / 88$ & -0.20 & $1.95^{* *}$ & 1.22 & -2.35 & $-1.66^{*}$ & 0.08 \\
\hline $86 / 88-89 / 91$ & -0.75 & 0.46 & -0.95 & 0.67 & -0.47 & $-1.36^{*}$ \\
\hline $89 / 91-92 / 94$ & $4.47^{* *}$ & $5.32^{* *}$ & $4.47^{* *}$ & -0.98 & 0.90 & $-1.60^{*}$ \\
\hline $92 / 94-95 / 97$ & 0.13 & $2.82^{* *}$ & $3.64^{\circ *}$ & $2.56{ }^{* *}$ & $\mathbf{3 . 5 8} 8^{* *}$ & $3.10^{* * *}$ \\
\hline $95 / 97-98 / 00$ & -1.49 & -0.63 & $-1.83^{* *}$ & $-1.60^{*}$ & -1.00 & $-2.21^{* *}$ \\
\hline $98 / 00-01 / 03$ & $2.22^{* *}$ & 0.48 & $7.50 *$ & -1.06 & $-3.68^{* *}$ & $-3.71^{* *}$ \\
\hline $01 / 03-04 / 06$ & $8.87^{* *}$ & $7.45^{* *}$ & $10.66^{* \prime}$ & $3.85^{* *}$ & 0.08 & 0.27 \\
\hline \multicolumn{7}{|c|}{ Panel B: analysis with only those mutual funds with a significant beta of coskewness } \\
\hline $62 / 64-65 / 67$ & -0.47 & $2.00^{* * *}$ & -0.33 & 0.00 & 1.24 & -1.01 \\
\hline $65 / 67-68 / 70$ & 0.47 & $1.99^{* *}$ & 1.06 & $1.55^{*}$ & $2.28 * *$ & $2.00 *$ \\
\hline $68 / 70-71 / 73$ & 0.24 & $2.21 * *$ & 1.30 & -0.42 & 0.94 & 0.30 \\
\hline $71 / 73-74 / 76$ & 0.31 & $1.43^{*}$ & $1.55^{\circ}$ & 0.85 & 0.68 & 0.79 \\
\hline $74 / 76-77 / 79$ & 0.26 & 0.81 & $1.56^{*}$ & 0.74 & 0.76 & $1.59^{*}$ \\
\hline $77 / 79-80 / 82$ & 0.53 & $1.76^{* *}$ & $3.12^{* *}$ & 0.19 & 1.06 & 0.39 \\
\hline $80 / 82-83 / 85$ & $1.55^{*}$ & $3.46^{* *}$ & $4.27^{\circ *}$ & 0.37 & $3.07^{* *}$ & $2.03^{* *}$ \\
\hline $83 / 85-86 / 88$ & $2.20^{* *}$ & $2.72^{* *}$ & $2.81^{\circ}$ & 0.86 & $1.38^{*}$ & $2.48^{* *}$ \\
\hline $86 / 88-89 / 91$ & 1.15 & $3.84^{* *}$ & $1.66^{*}$ & 1.29 & 1.13 & $3.06{ }^{* *}$ \\
\hline $89 / 91-92 / 94$ & $3.43^{* *}$ & $5.85^{* *}$ & $6.19 *$ & 1.24 & $2.96^{* *}$ & $3.61^{* *}$ \\
\hline $92 / 94-95 / 97$ & $2.08^{* *}$ & $5.75^{* *}$ & 7.10 & $3.70^{* *}$ & $4.07^{* * *}$ & $4.37^{* *}$ \\
\hline $95 / 97-98 / 00$ & $-1.73^{* * *}$ & $2.03^{* * *}$ & $1.64^{\circ}$ & 0.90 & 1.37 & $3.13^{*}$ \\
\hline $98 / 00-01 / 03$ & $3.91^{* *}$ & $4.41^{* *}$ & $12.75^{\circ *}$ & -0.87 & -0.55 & $-1.73^{* *}$ \\
\hline $01 / 03-04 / 06$ & $10.82^{* * *}$ & $8.57^{* *}$ & $14.89^{\circ *}$ & $3.24^{* * *}$ & $3.588^{* * *}$ & $5.91^{* *}$ \\
\hline
\end{tabular}

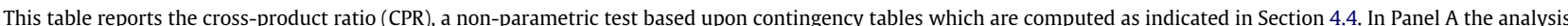

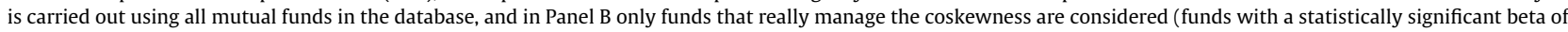

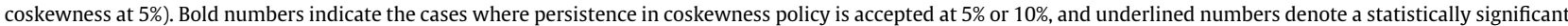
reversal in coskewness policy at $5 \%$ or $10 \%$.

" Indicates statistical significant at 5\%.

** Shows statistical significant at $10 \%$. 
Table 10

Means of the mutual fund characteristics grouped by coskewness.

\begin{tabular}{|c|c|c|c|c|c|}
\hline Variables & & $S$ & $S^{0}$ & $S^{+}$ & Equally test \\
\hline \multirow{3}{*}{ TNA } & $1962-1976$ & 7.376 & 7.457 & 7.957 & 0.200 \\
\hline & $1977-1991$ & 7.523 & 7.748 & 7.683 & 0.592 \\
\hline & 1992-2006 & 6.596 & 6.648 & 6.648 & 0.624 \\
\hline \multirow[t]{3}{*}{ Expenses } & $1962-1976$ & 0.009 & 0.009 & $0.007^{* *}$ & 0.002 \\
\hline & $1977-1991$ & 0.011 & 0.011 & 0.011 & 0.585 \\
\hline & $1992-2006$ & $0.015^{* * *}$ & 0.014 & 0.014 & 0.004 \\
\hline \multirow[t]{3}{*}{ Turnover } & $1962-1976$ & $0.837^{*}$ & 0.642 & 0.491 & 0.002 \\
\hline & 1977-1991 & 0.680 & 0.823 & 0.850 & 0.091 \\
\hline & 1992-2006 & $0.856^{* *}$ & 0.953 & 0.948 & 0.078 \\
\hline
\end{tabular}

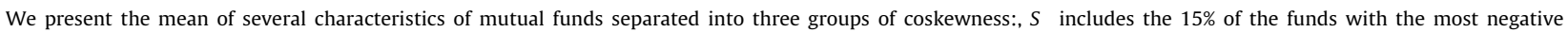

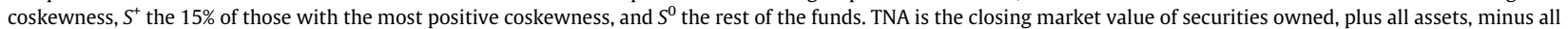

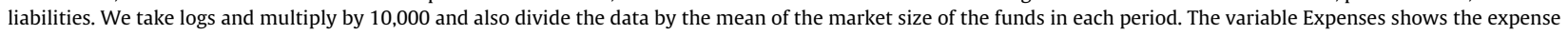

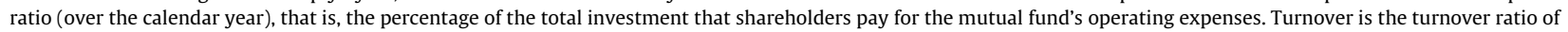
the fund (over the calendar year), that is, the minimum of aggregate purchases of securities or aggregate sales of securities, divided by the average TNA of the fund.

" Indicates the rejection, at $90 \%$.

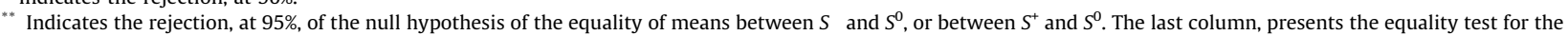
means of the groups $S$ and $S^{+}$.

Table 11

Relation between characteristics of funds and coskewness.

\begin{tabular}{|c|c|c|c|c|c|c|c|c|}
\hline $\begin{array}{l}\text { Variable } \\
S=1\end{array}$ & Marg. Prob. & $p$-Val. & $\begin{array}{l}\text { Variable } \\
S=1\end{array}$ & Marg. Prob. & $p$-Val. & $\begin{array}{l}\text { Variable } \\
S=1\end{array}$ & Marg. Prob. & p-Val. \\
\hline Panel A: 1962-1976 & & & Panel B: 1977-1991 & & & Panel C: 1992-2006 & & \\
\hline Intercept & -1.029 & 0.533 & Intercept & -1.485 & 0.215 & Intercept & -1.651 & $<0.000$ \\
\hline TNA & -0.042 & 0.79 & TNA & -0.069 & 0.534 & TNA & -0.011 & 0.626 \\
\hline Turnover & 1.239 & 0.01 & Turnover & -0.604 & 0.025 & Turnover & -0.359 & $<0.000$ \\
\hline Expenses & -84.69 & 0.317 & Expenses & 27.433 & 0.487 & Expenses & 9.361 & 0.221 \\
\hline DB1 & -1.508 & 0.075 & DB1 & 0.958 & 0.01 & DB1 & 0.959 & $<0.000$ \\
\hline DB2 & -0.523 & 0.354 & DB2 & 0.876 & 0.018 & DB2 & -0.22 & 0.094 \\
\hline$S^{+}=3$ & & & $S^{+}=3$ & & & $S^{+}=3$ & & \\
\hline Intercept & 1.513 & 0.42 & Intercept & -1.58 & 0.066 & Intercept & -1.332 & $<0.000$ \\
\hline TNA & -0.2069 & 0.193 & TNA & -0.04 & 0.643 & TNA & -0.005 & 0.797 \\
\hline Turnover & 0.452 & 0.541 & Turnover & 0.207 & 0.302 & Turnover & 0.1603 & 0.007 \\
\hline Expenses & -301.19 & 0.006 & Expenses & 4.268 & 0.902 & Expenses & -3.971 & 0.585 \\
\hline DB1 & -1.11 & 0.368 & DB1 & -0.379 & 0.314 & DB1 & -1.423 & $<0.000$ \\
\hline DB2 & 1.426 & 0.003 & DB2 & 0.687 & 0.034 & DB2 & 0.131 & 0.186 \\
\hline Number of obs. & 169 & & Number of obs. & 411 & & Number of obs. & 4688 & \\
\hline Wald $\chi^{2}(10)$ & 28.53 & & Wald $\chi^{2}(10)$ & 23 & & Wald $\chi^{2}(10)$ & 345 & \\
\hline Prob $>\chi^{2}$ & 0.0015 & & Prob $>\chi^{2}$ & 0.0107 & & Prob $>\chi^{2}$ & $<0.000$ & \\
\hline Log likelihood & -121.4 & & Log likelihood & -324.51 & & Log likelihood & -3658 & \\
\hline Pseudo $R^{2}$ & 0.115 & & Pseudo $R^{2}$ & 0.034 & & Pseudo $R^{2}$ & 0.05 & \\
\hline
\end{tabular}

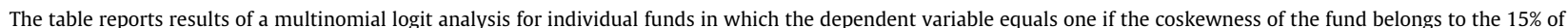

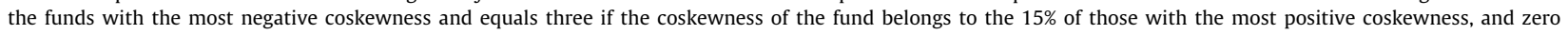

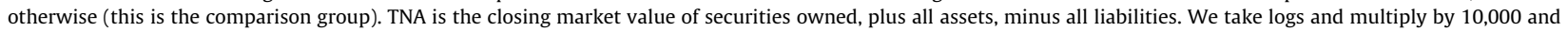

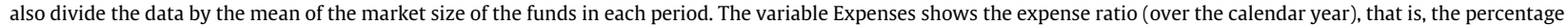

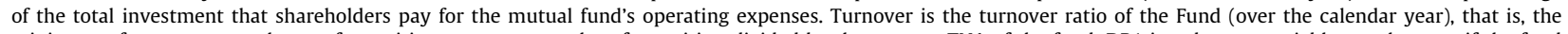

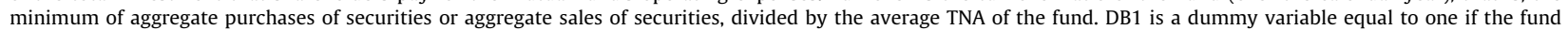

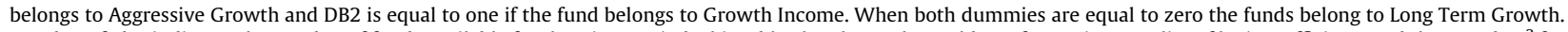

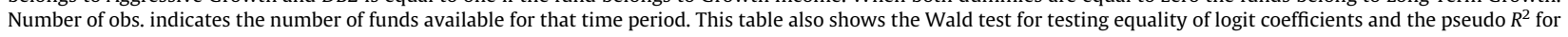
the regressions.

tal Net Assets (TNA), Expenses, and Turnover, obtained from the CRSP database.

The variable TNA is the closing market value of securities owned, plus all assets minus all liabilities. TNAs from CRSP are re ported in millions of dollars; logs are taken and multiplied by 10,000. Given that mutual fund sizes have been growing with time, in order to achieve a good measure of the relative size of each mu tual fund, the data is divided by the mean of the market size of the funds in each period. Turnover is the turnover ratio of the fund (over the calendar year), that is, the minimum of aggregate pur chases of securities or aggregate sales of securities divided by the average TNA of the fund. The variable Expenses shows the expense ratio (over the calendar year), that is, the percentage of the total investment that shareholders pay for the mutual fund's operating expenses. Given the differences over time of some characteristics, such as fund size, the sample is split into three periods: from 1962 to 1976, from 1977 to 1991, and from 1992 to 2006.

Results from the univariate analysis are presented in Table 10. Columns 3, 4, and 5 report the mean of every characteristic in each period. The equality of the means has been tested and $\left({ }^{* *}\right)$ indicates the rejection, at the $95 \%$ level of the null hypothesis, of the equality of means between $(S)$ and $\left(S^{0}\right)$ or between $\left(S^{+}\right)$and $\left(S^{0}\right)$. The last column presents the equality test for the means of the groups $(S)$ and $\left(S^{+}\right)$. Thus, for the first characteristic analyzed, TNA, and for all periods, it is smallest for funds managing the negative coskewness (funds in groups $(S)$. However, the mean equality test indicates that the average sizes are not statistically different among the three groups of coskewness. Expenses for funds in $\left(S^{+}\right)$ 
are the lowest in the first period, the means being statistically dif ferent. In the last period, Expenses for the funds in (S ) are higher than in the rest. Finally, the Turnover mean is statistically different between the groups $(S)$ and $\left(S^{0}\right)$ in the last period, being lowest for funds with a negative coskewness. Moreover, in all periods the Turnover mean is statistically different between $\left(S^{+}\right)$and $(S)$.

The univariate analysis indicates some differences related to coskewness in the characteristics of funds. To clarify the influence on the coskewness of all these characteristics together, a logit anal ysis is performed. Logit can be viewed as a generalization of the linear regression model to situations where the dependent variable takes on only a finite number of discrete values. Thus, the depen dent variable is a dummy variable equal to one if the fund belongs to the $15 \%$ of the data with the most extreme negative coskewness (S ), three if the fund belongs to the $15 \%$ with the most positive coskewness $\left(S^{+}\right)$, and two for the rest, that is $S^{0}$ (the comparison group). The reason for a logit analysis is to estimate the probability of a fund having a significant coskewness conditional on the explanatory variables. The negative (positive) sign of the coeffi cient of a characteristic indicates that this characteristic has a neg ative (positive) impact on the probability of significantly managing coskewness.

In addition to the characteristic considered in the previous uni variate analysis and in order to address the different role of fund categories in the coskewness observed in Table 4, an explanatory variable is included: a dummy variable equal to one where the fund belongs to Aggressive Growth (DB1) and another dummy var iable equal to one where the fund belongs to Growth Income (DB2). When both dummies are equal to zero the funds belong to Long Term Growth.

There are two main results from Table 11 for the last two subs amples (Panels B and C). ${ }^{20}$ First, increasing the turnover ratio of the funds decreases the probability of having a significant negative coskewness and increases the probability of having a significant po sitive coskewness. One interpretation is that fund managers who are managing the coskewness and profiting from the coskewness spread are managing funds more passively. Second, being an Aggressive Growth fund increases the probability of having negative coskew ness and decreases the probability of having a positive and signifi cant coskewness. Finally, the TNA and the expense ratio are not significant variables in explaining the coskewness of the funds.

\section{Concluding remarks}

Recent asset pricing studies show that systematic skewness is important and that it helps to explain the time variation of risk premiums. This paper explores the role of coskewness in the anal ysis of mutual fund performance evaluation by examining a sample of 6819 equity mutual funds between January 1962 and December 2006.

The results demonstrate that incorporating a coskewness factor as an additional variable increases the explanatory power of the model in both an unconditional and a conditional framework. The coskewness factor is significant even when factors based on size, book to market value, and momentum are included. There fore, failure to consider systematic skewness could create a poten tial problem of specification that could bias the risk adjusted return obtained by mutual funds, providing investors with inaccu rate information about the past performance of mutual fund managers.

\footnotetext{
20 The great difference in the number of available funds during the last two periods and the first one $(169,411$, and 4688 observations respectively) allows more confidence in the results obtained from the latter two periods.
}

A highlight of this analysis is that, in general, there is evidence of significant changes in mutual fund performance when system atic skewness is taken into account. The sign of the variation in the performance is determined by the loading on the coskewness factor. Thus, if the beta of the coskewness factor is positive, indicat ing greater exposure of the fund to assets with negative coskew ness, the adjusted alpha will decrease, whereas a negative loading in the coskewness factor increases the alpha. These changes in performance are statistically significant in $80 \%$ of the mutual funds sampled when the coskewness is introduced in the CAPM, and are statistically significant for between $20 \%$ and $40 \%$ in the FF4 model. Furthermore, a ranking based on risk adjusted returns without considering coskewness will generate a mislead ing classification and may have serious implications for other mu tual fund research where performance ranking is required, such as performance persistence studies or studies of investors' selection ability and flows of mutual funds.

Finally, this paper documents that once managers have decided to employ a certain policy of coskewness, betting on assets with positive or negative coskewness, they continue with that policy over time. The next step identifies which class of funds uses one policy or another, through a logit analysis. Some fund characteris tics are related to the likelihood of managing coskewness: the turnover ratio the fund managers who are managing the coskew ness and profiting from the coskewness spread are managing the more passive funds and the category indicator.

\section{Acknowledgements}

We thank Wayne Ferson, Sergio Mayordomo, J. Carlos Matallín, Miguel Angel Martinez, J. Ignacio Peña, Gonzalo Rubio, Pablo Ruiz Verdu, and participants in the 11th International Conference Fore casting Financial Markets, ESCP EAP Seminar Series and the XII Foro de Finanzas, for helpful comments and suggestions from a previous version of this paper. The contents of this paper are the sole responsibility of the authors. David Moreno acknowledges the financial support provided by the Ministerio de Ciencia y Tec nología grant SEJ2007 67448. Rosa Rodríguez acknowledges the financial support provided by the Ministerio de Ciencia y Tec nología grant SEJ2006 09401.

\section{References}

Ang, J.S., Chua, J.H., 1979. Composite measures for the evaluation of investment performance. Journal of Financial and Quantitative Analysis $14,361-384$.

Bali, T.G., Mo, H., Tang, Y., 2008. The role of autoregressive conditional skewness and kurtosis in the estimation of conditional VaR. Journal of Banking and Finance 32, 269-282.

Barone-Adesi, G., Gagliardini, P., Urga, G., 2004. Testing asset pricing models with coskewness. Journal of Business and Economic Statistics 22, 474-485.

Carhart, M., 1997. On persistence in mutual fund performance. Journal of Finance $52,57-82$

Chen, Z., Knez, P.J., 1996. Portfolio performance measurement: Theory and applications. Review of Financial Studies 9, 511-555.

Christensen, R., 1990. Log-Linear Models. Springer Verlag, New York.

Christie-David, R., Chaudhry, M., 2001. Coskewness and cokurtosis in futures markets. Journal of Empirical Finance 8, 55-81.

Christopherson, J.A., Ferson, W.E., Glassman, D.A., 1998. Conditioning manager alphas on economic information: Another look at the persistence of performance. Review of Financial Studies 11, 111-142.

Chung, Y.P., Johnson, H., Schill, M.J., 2006. Asset pricing when returns are nonnormal: Fama-French factors versus higher-order systematic components. The Journal of Business 79 (2), 923-940.

Ding, B., Shawky, H.A., 2007. The performance of hedge fund strategies and the asymmetry of return distributions. European Financial Management 13 (2), 309-331.

Efron, B., Tibshirani, R.J., 1993. An Introduction to the Bootstrap. Monographs on Statistics and Applied Probability. Springer.

Fama, E.F., French, K.R., 1993. Common risk factors in the returns on stocks and bonds. Journal of Financial Economics 33, 3-56.

Ferson, W.E., Schadt, R.W., 1996. Measuring fund strategy and performance in changing economic conditions. Journal of Finance 51, 425-461. 
Ferson, W.E., Warther, V.A., 1996. Evaluating fund performance in a dynamic market. Financial Analysts Journal 52, 20-28.

Frino, A., Lepone, A., Wong, B., 2009. Derivative use, fund flows and investment manager performance. Journal of Banking and Finance 33, 925-933.

Harvey, C.R., Siddique, A., 2000. Conditional skewness in asset pricing tests. Journal of Finance 55, 1263-1295.

Jensen, M.C., 1968. The performance of mutual funds in the period 1945-1964 Journal of Finance 23, 389-416.

Klemkosky, R.C., 1973. The bias in composite performance measures. Journal of Financial and Quantitative Analysis 3, 505-514.

Koski, J.L., Pontiff, J., 1999. How are derivatives used? Evidence from the mutual fund industry. Journal of Finance 54 (2), 791-816.

Kraus, A., Litzenberger, R.H., 1976. Skewness preference and the valuation of risk assets. Journal of Finance 31, 1085-1100.

Leland, H.E., 1999. Beyond mean-variance: Performance measurement in a nonsymmetrical world. Financial Analyst Journal 55 (1), 27-36.

Moreno, D., Rodríguez, R., 2006. Performance evaluation considering the coskewness: A stochastic discount factor framework. Managerial Finance 32 (4), 375-392.
Prakash, A.J., Bear, R.M., 1986. A simplifying performance measure recognizing skewness. Financial Review 21, 135-144.

Post, T., Van Vliet, P., Levy, H., 2008. Risk aversion and skewness preference. Journal of Banking and Finance 32, 1178-1187.

Ranaldo, A., Favre, L., 2005. How to price hedge funds: From two- to four-moment CAPM. USB Research Paper.

Sharpe, W.F., 1966. Mutual fund performance. Journal of Business 39, 119-138.

Smith, D., 2007. Conditional coskewness and asset pricing. Journal of Empirical Finance 14 (1), 91-119.

Stephens, A., Proffitt, D., 1991. Performance measurement when return distributions are nonsymmetric. Quarterly Journal of Business and Economics $30,4-23$.

Treynor, J.L., 1965. How to rate management of investment funds. Harvard Business Review 43, 63-75.

Vanden, J.M., 2006. Option coskewness and capital asset pricing. The Review of Financial Studies 19 (4), 1279-1320.

Vines, T.W., Cheng-Ho, Hsieh, Hatem, J., 1994. The role of systematic covariance and coskewness in the pricing of real estate: Evidence from equity REITs. Journal of Real Estate Research 9, 421-429. 